\title{
Teaching Research and Practice of Information Technology Course Based on Project Teaching Method
}

\author{
Yu'e Song \\ Yantai Academy \\ China Agricultural University \\ Yantai, China 264670 \\ School of Electrical and Information Engineering \\ Beijing Polytechnic College \\ Beijing, China 100042 \\ Chunhui Sun \\ Yantai Urban and Rural Construction School \\ Yantai, China 264004
}

\author{
Xiaofeng Chen \\ Yantai Academy \\ China Agricultural University \\ Yantai, China 264670
}

\author{
Chengguo Wang* \\ Yantai Academy \\ China Agricultural University \\ Yantai, China 264670 \\ *Corresponding Author
}

\begin{abstract}
Project teaching method is an effective combination of theoretical teaching and practical teaching methods, and it is an indispensable teaching method in contemporary higher education. This innovative teaching method requires students to actively participate in the study of typical projects. It can bring interest to students in learning and cultivate creative thinking of the students, and emphasize the main position of the students in teaching activities. This paper describes the teaching process of the project teaching method applied in the course of information technology, and obtains good teaching effect in practical application.
\end{abstract}

Keywords-project teaching method; bilingual education; teaching reform

\section{INTRODUCTION}

The course "Introduction to Information Technology" is the first computer public basic course for all majors in colleges and universities, which provides students with an introductory introduction to computer science, so that they can have a holistic understanding of the subject, and understand the basic knowledge and skills that students in the profession should have, as well as the professional ethics and legal norms that should be observed in the field.

This course is a combination of computer basic theory and application operation, which covers all aspects of computer science and requires breadth first. Through this course's study, can expand the student's field of vision, prepares the necessary knowledge for the follow-up course study, so that they can consciously draw lessons from and introduce some ideas, techniques and methods in the computer science in their respective professions, expect them to use the computer at a higher level, Recognize and deal with problems that may arise in computer applications.

Project teaching method is also called the Interdisciplinary course, which is taught through the form of "project". To enable students to get used to solving problems in a complete way, the "project" set up contains knowledge of multiple courses. The project teaching method is under the teacher's guidance; leave a relatively independent project to the students themselves. Information collection, program design, project implementation and final evaluation, all by the students themselves, students through the project, understand and grasp the entire process and the basic requirements of each link.

\section{PRoJeCt TEACHING METHOD}

Project teaching method is to divide a specialized course into several technical or skill units by category, each technology or skill unit as a teaching project, the implementation of the theory, the practice of integrated modular teaching, each unit teaching with the application of the technology or skills to complete a job to end, and the next project teaching. In short, project teaching is the teaching action that teachers and students carry out in order to complete a specific task. Project teaching is a method and a scheme.

The characteristics of "project teaching method":

- The teaching content: no longer use the previous "knowledge Point" as a clue to the way, but according to the reception ability of the students and the demand of the information age, instead of "project" as the 
Clue, the "subproject" as the module, carefully organize the teaching content, so that it conforms to the cognitive characteristics of the students, especially to emphasize that the knowledge must be synchronized with the times.

- The teaching method: Emphasizing the students ' independent study and exploration, emphasizing the cultivation of students' self-study ability. In the course of teaching in accordance with the "project" needs to learn, the passive acceptance of knowledge as the initiative to seek knowledge, change the traditional learning concept of students, from "learn" to "will learn".

- The capacity-building: to cultivate the innovative spirit and cooperative consciousness of the students, students will actively think and explore in the process of completing "project". The ideas are not the same, teachers can guide them to discuss and exchange, and appropriate to give comments and encouragement, so that they complement each other, not only mobilize and students enthusiasm, but also cultivate their innovative spirit and cooperation consciousness.

- The employment direction, the projects taken are all from the actual work.

\section{PROJECT DESIGN AND SELECTION}

The development of project teaching method needs some steps, its mode is completely different from the traditional teaching mode, paying more attention to autonomy and practicality of the students, and developing the mode is often the group cooperation of the students. The project teaching method is generally divided into four steps according to the teaching content design related project, according to the design project specific assignment related task, the concrete implementation stage, completes the Project Practice report and summarizes.

Based on the teaching concept of "two-way complementarity between teaching and learning", the information Technology Course group insists on emphasizing: to develop the field of vision and to stimulate self-learning and collaborative learning of the students with a series of experiments. Consider the course content close to life, and the different characteristics of the starting point of the students, planning the content of the curriculum, design a series of experiments, to establish the responsibility of teachers, and to group students, pay attention to the personality training of the students, encourage "top-notch", guide in-depth, at the same time guide "top-notch" students to Therefore, the choice and design of the project to consider the following two aspects: first, the size of the project is moderate, can cover all aspects of information technology, the second is the students to be familiar with the project, or can be quickly familiar with the project.

\section{SPECIFIC IMPLEMENTATION OF THE PROJECT}

The project teaching method advocates to speak first, to learn to teach, emphasizing autonomous learning of the students, active participation, starting from the practice, mobilizing initiative the students, creativity, enthusiasm, and so on, the students sing "protagonist", and the teacher into "Supporting role", to achieve the transposition of teachers ' roles, is conducive to strengthening the students self-learning ability, The cultivation of innovative ability. The author has carried on the tentative research and the practice to the project teaching method in many aspects, also has obtained the certain effect.

In order to develop the ability of the students to collaborate in a team, the group will complete the project in the form of a grouped group, each of which controls 5 to 6 people, and elects a team leader to be responsible for the overall planning of the project and the Division of tasks of the team members. Encourage discussion and develop relevant planning, and to give full play to the strengths of different students so that they can complete the project more satisfactorily.

The project teaching method is the teacher instructs the student activity, usually in 50 minutes time, the teacher lectures only accounts for $40 \%$ or so time, the remaining time, all by the student under the teacher's instruction completes certain task. According to the actual situation of the course, using modular design ideas, the whole course from the use of software to the module design into six parts, such as in "Table I". For each module, the teachers mainly explain the ideas, the main use of the technology and matters needing attention. Each group of students according to the teacher, through discussion, checks information and other methods to complete the module. For students in the implementation of the project module if the problem is not resolved, you can consult the teacher, by the teacher to carry out specific guidance and answers. Each team completes each function module according to the teacher's arrangement, and finally completes the whole project.

TABLE I. COURSE MOdULE DESCRIPTION

\begin{tabular}{cll}
\hline Number & \multicolumn{1}{c}{ Module } & \multicolumn{1}{c}{ Description } \\
\hline $\mathbf{1}$ & $\begin{array}{l}\text { Basics of } \\
\text { Information } \\
\text { Technology } \\
\text { Operating } \\
\text { System } \\
\text { Word }\end{array}$ & $\begin{array}{l}\text { Understanding the representation of } \\
\text { numbers in computers and information } \\
\text { coding } \\
\text { Skilled in using the latest operating } \\
\text { system }\end{array}$ \\
$\mathbf{3}$ & $\begin{array}{l}\text { Processing } \\
\text { Using Word software to edit text }\end{array}$ \\
$\mathbf{4}$ & $\begin{array}{l}\text { Presentation } \\
\text { Working with data using Excel software } \\
\text { Making a presentation with PowerPoint } \\
\text { software } \\
\text { mastering the connection and settings of } \\
\text { the network, the use of browsers, the use } \\
\text { of e-mail, the way to upload and } \\
\text { download files, and the search methods } \\
\text { of network information. }\end{array}$ \\
& $\begin{array}{l}\text { Fundamentals } \\
\text { of Network } \\
\text { Technology }\end{array}$ \\
& $\begin{array}{l}\text { Multimedia } \\
\text { technology }\end{array}$ & $\begin{array}{l}\text { Understanding the digital process of } \\
\text { sound, image, and video }\end{array}$ \\
\hline
\end{tabular}

\section{PROJECT SUMMARY AND COMMENT}

In the course of teaching, teachers ' knowledge and skills are no longer passed on to students as the goal of pursuit, or it is not simple to let the students get a result according to the teacher's arrangement and teaching, but under the guidance 
of the teacher, the students find the way to get the result, finally get the result, and show and self-evaluation, The focus of learning is on the learning process rather than the results of the study, and they exercise various abilities in the process. The teacher is not the subject position in the teaching, but becomes the guide, the instructor and the supervisor in the student's learning process; the student has $90 \%$ enthusiasm.

\section{CONCLUSION}

Project teaching method is an effective combination of theoretical teaching and practical teaching methods, through the implementation of a complete project, so that students have comprehensive information technology courses to understand and understand, for the future information related professional learning to lay a good foundation. At the same time, the project decomposition into functional modules, conducive to the development and design of projects, in other projects have the same or similar functional modules, can be directly used, or part of the modification, can improve work efficiency. Through the implementation of Project teaching method, students actively participate in the analysis and study of typical modules, stimulate the interest of the students in learning and cultivate creative thinking of the students, highlight the students in the teaching activities of the main position, conducive to the mastery and use of knowledge, and achieved good results.

\section{ACKNOWLEDGEMENT}

This research was financially supported by Beijing Natural Fund Project (4164107), and the automatic control principle high quality course construction project of Yantai Academy of China Agricultural University (201612ka).

\section{REFERENCES}

[1] Wang Chengguo, Liu Shuguang, Yu Xitao, etc. The teaching research of the course of automatic control principle in the specialty of facility agriculture [J]. Agricultural network information, 2016, (01): 111-113.

[2] Feng Jingyi. Research on the application of Project teaching method in the training of Android programming [J]. Electronic science and technology, 2017, 04 (03): 129-132.

[3] Zhang Qiyu, Sun Chunhui, Wang Chengguo. Application of Project teaching method in dynamic website course [J]. Agricultural network information, 2015, (08): 127-128+142.

[4] Qiang Shuxiang. Teaching practice of "Server Configuration and Management" course based on project teaching method [J]. Information Systems Engineering, 2017, (01): 173-174.

[5] Tian Zhenkun. The theory of Project pedagogy and its implementation in computer courses--a case study of China Labor Relations College [J]. Journal of China Institute of Labor Relations, 2016, 30 (03): 122-125.

[6] Guo Xiaoqing, Zhu Shuxin, Shai Zhonghong,etc. A study on the gradual project case teaching method with the aim of training excellent engineers--taking Java experimental teaching as an example [J]. University laboratory work Research, 2016, (02): 10-12.

[7] Liu Xiaozhong. The course teaching research of "network operating system" based on Project teaching method [J/ol]. Computer knowledge and technology, 2016, 12 (22): 120-121. 